\title{
Risk Identification and Prevention and Control Measures of Urban Rail Transit Construction
}

\author{
Zhongda Wang*
}

Sihao Rail Technology Co., Ltd. E-mail: zhongda@163.com

\begin{abstract}
Urban rail transit is a key bridge to promote the sustainable development of national economy. The risk problems existing in the actual construction process will have a negative impact on the rail transit to play its own role, and it is closely related to the stable development of the country and society. Based on this, this paper probes into the risk identification of urban rail transit engineering construction in order to provide corresponding reference for future research.
\end{abstract}

Keywords: Urban Rail Transit Engineering; Construction and Construction; Risk Identification

\section{Introduction}

With the arrival of China's modern society, the number of urban population gradually increases, which leads to some problems in urban transportation, such as heavy traffic and frequent safety accidents. Under such circumstances, during the actual construction of urban rail transit projects, relevant personnel should identify the existing risks and take scientific and reasonable measures and solutions. Only in this way can we promote the healthy and sustainable development of China's transportation industry and its continuous development towards modernization.

\section{The practical significance of risk identification in urban rail transit engineering construction}

At present, there are still many risk problems in the concrete construction process of the project, which have a negative impact on improving the overall quality and an effect of the project and economic benefits and social values for enterprises. Its specific content is mainly reflected in the construction of rail transit engineering, which is related to many fields. This kind of project is a comprehensive project that mainly includes many types of projects and many large-scale projects. Strengthening the construction of this kind of project can ensure the smooth development of the construction operation after this project. In actual construction, if there is a problem in a certain link, it is very easy to cause serious safety accidents. Besides, it takes about 5 6 years in the actual construction process of the project, and during this time, if no corresponding supervision mechanism is formed, many safety problems will arise. It is worth paying attention to that the construction of urban rail transit projects are mainly in densely populated areas, and its traffic conditions and environment are very complicated. At the same time, the construction facilities and equipment are huge, and the geological conditions of the construction site are very complicated, which leads to high-risk problems in the actual construction process of using facilities and equipment. Under such circumstances, the emergence of risk problems should be prevented, and

Copyright (C) 2020 Zhongda Wang

doi: $10.18686 /$ utc.v6i1.82

This is an open-access article distributed under the terms of the Creative Commons Attribution Non-Commercial License

(http://creativecommons.org/licenses/by-nc/4.0/), which permits unrestricted non-commercial use, distribution, and reproduction in any medium,

provided the original work is properly cited. 
many risk factors existing in safety are taken into account with scientific and reasonable measures and methods to avoid them after comprehensively exploring and analyzing these risk problems. At present, in the actual construction process of urban rail in China, it is necessary to realize the innovation and change of science and technology and to make full use of advanced construction technology, which can better prevent the emergence of safety risks. When ensuring the normal operation of rail transit projects, it can finally achieve the successful completion date to ensure the safety of people's lives and property with scientific and reasonable reference for the construction of related projects in China.

\section{Analysis of the characteristics of urban rail transit engineering construction}

In order to ensure the normal operation of the project, it will take at least 5 years, so the time spent in the actual construction of the project is very long, and there are many risk problems in each link. Because there are many related fields, long construction time and more investment in current project construction, there will be more risk problems in its construction operation. Specifically, there are potential risks in every link of construction activities. Under such circumstances, these risk problems should be eliminated to avoid unnecessary losses and risk problems as much as possible. At the present stage, there are some differences in the advanced technologies mastered by relevant personnel in relevant markets, and the construction techniques mastered are also different. New technologies and new construction techniques are often used in the actual construction process, which leads to many risks faced by construction personnel. Considering this phenomenon, relevant personnel need to comprehensively explore and analyze the risks in the specific construction activities of rail transit projects. Only in this way can these risks be better avoided in actual construction.

\section{Risk identification and analysis of urban rail transit engineering construction}

\subsection{Geological and hydrological conditions}

The basic conditions for the success of shield engineering are accurate, detailed and complete geological and hydrological data of the whole line. The success or failure of shield engineering depends on the completeness of geological prospecting report. Geological and hydrological data determines the feasibility of adopting shield, the selection of shield, the main parameters of shield, the selection of equipment for auxiliary construction of shield machine and the preparation of corresponding emergency plans in the early stage of shield construction. Main geological risks of shield construction are: (1) Composite strata (Guangzhou, Shenzhen and Nanjing); (2) Karst caves and earth caves (northern Guangzhou, Foshan, northern Shenzhen and Guiyang); (3) Extremely wear-resistant siliceous and iron cuttings (Guangzhou and Nanjing); (4) Silty fine sand layer containing confined water (Guangzhou, Foshan, Shanghai, Nanjing, Suzhou and Hangzhou); (5) Gas and coal-formed gas (Guangzhou, West, South, Hangzhou, Wuhan); (6) Gravel stratum (Shenyang, Beijing, Chengdu, Nanning, Nanchang, $\mathrm{Xi}$ 'an and Guangzhou); (7) Cohesive soil and mudstone caking cake, interbedded sandstone and mudstone with uneven hardness and fragmentation (Chongqing, Guangzhou, Shenzhen, Nanchang and Hefei).

\subsection{Shield equipment}

Professional manufacturing and advanced technology can ensure that shield tunneling construction is safer, more efficient and more reliable, and they reduce shield construction risks. Tunnel engineering risks need rich experience to deal with, including technical support and spare parts supply. Shield risks are: (1) Shield type selection and functional defects; Mud water or earth pressure; design value of driving force and torque; opening ratio (large opening ratio is adopted in gravel layer); cutter configuration and cutter type, cutter spacing and cutter difference design; ballast soil improvement device and synchronous grouting system with pressure inlet system. (2) The main bearing or seal is damaged. (3) Cutter head damage (disintegration, cracking and wear). (4) The reduction gearbox and gear transmission system are damaged. In order to ensure the construction period of shield construction project, 
scientific construction management can reduce tunneling cost and generate benefits for the project. The main man-made risks are: (1) Failure to fully and systematically understand geological changes and shield performance; (2) Construction organization and sense of responsibility: (3) Rationality of construction scheme and measures.

\section{Urban rail transit engineering construction prevention and control measures}

\subsection{Geological survey accuracy}

Geological robbery with high accuracy can reflect the geological conditions of the tunnel section, which is not only conducive to the correct selection of shield machines, but also to tunnel propulsion. Geological survey holes are generally $30 \mathrm{~m}$ apart on the tunnel axis, and the interval distance can be determined according to the requirements when the formation conditions are complex.

\subsection{Stratum adaptability of shield machine}

Selection and design of shield machine should be carried out according to the principle of "Reliability first, technological advancement second and economy third". Before the shield machine is manufactured or determined, the local expert demonstration meeting shall be organized, and the shield machine shall be purchased and finalized according to the opinions of the expert meeting. According to the statistics of construction accidents, major accidents are easy to occur in the initial and receiving stages, and major accidents such as water gushing and sand gushing in the stratum with abundant groundwater are also easy to occur, which will cause irreversible losses to the project cost and company image. After the end reinforcement, it should meet the requirements of soil strength, stability, permeability (water, sand, and pressure) and deformation characteristics (after the earth pressure disappears). When there is a large water pressure above the shield tunnel or the overlying soil is less than 1 times the shield diameter, it is more likely that some tunnels in this section will float upwards, so some measures should be taken to prevent the tunnel from floating upwards and to avoid causing engineering quality problems (geological risk and man-made risk).

\subsection{The main measures taken are as follows}

(1) Slurry with adjustable gelation time or hard slurry with large sand content are adopted. (Inert grout is generally used in synchronous grouting construction. This grout has a large amount of bleeding water and no strength, which will cause the segment to float upwards, the tunnel settlement in the later period is large, and the ground houses crack). (2) According to the feedback of daily measurement report, in the process of advancing, in order to ensure that the deviation of tunnel axis is controlled within the allowable range of design, the upper partition pressure can be appropriately higher than the lower partition pressure, so that the tunneling axis is appropriately lower than the tunnel design axis. (3) Secondary grouting shall be carried out for 10 ring segments after the shield tail, and double grout shall be injected every 5 10 rings to make water stop hoop, so as to reduce the floating of the tunnel.

\subsection{Card shield tail}

In the process of shield tunneling, due to the change of formation pressure, passive hinge pressure or active hinge pressure is not paid attention to, and the soil around the shield shrinks, so that the friction between shield shell and soil is too large and the phenomenon of shield tail sticking appears (geological risk and equipment risk). A common phenomenon of shield sticking is that the tail shield is stuck. (1) use hydraulic jack to increase jacking force; (2) design a set of pressurization circuit for shield articulated system to increase the pulling force of articulated oil cylinder on shield tail. Strengthening geological exploration can prevent and control geological risks, including shield risk from shield adaptive design and man-made risks from professional control.

\subsection{Adaptability design of shield machine}

Dig into a fast and effective excavation of the front soil; It is concluded that the excavated rock and soil are quickly discharged; Stabilizing the front soil can ensure the stability of the excavation face. Long-term durability-high reliability of key components is suitable for long-distance construction. Taking EPB shield as an example: the cutter head structure, the cutter selection 
and arrangement are reasonable. The design of ballast soil improvement system and screw conveyor are reasonable. Design of key components with high reliability and long life. Spoke cutter head is suitable for driving in sand layer, gravel layer and small gravel sand pebble layer. Composite cutter head is suitable for rock stratum excavation. Small panel spoke cutter head is suitable for clay layer excavation. Spoke composite cutter head is suitable for driving large gravel layer. Tool configuration in different cities and strata are. (1) Shaft screw machine is selected for soft soil and sand layer (slag is discharged from lower single gate); (2) Axial screw machine (tail slagging method) is selected for water-rich formation; (3) Belt screw machine shall be selected for gravel stratum with large gravel diameter. Stable refers to the suitable muck improvement systems, including foam injection system, bentonite injection system and polymer injection system. Good improvement of ballast soil is one of the best methods to reduce tool wear, Stability of excavation face and smooth soil discharge are enhanced and torque and thrust are reduced during excavation.

\subsection{Muck improvement system}

Stable refers to the suitable muck improvement systems, including foam injection system, bentonite injection system and polymer injection system. Good improvement of ballast soil is one of the best methods to reduce tool wear, stabilize excavation face, discharge soil smoothly and reduce torque and thrust during excavation. (1) Foam system. Foam injection system is often used in soils with high proportion of fine particles, such as clay. It is mainly used to improve the fluidity, water retention and water tightness of muck; Specifically, the improved muck with better drainability can reduce the torque of cutter head andthe loss of water in formation and the risk of mud cake formation. (2) Bentonite system. Bentonite injection system is often used in soils with low proportion of fine particles, such as sandy pebble stratum. It is mainly used to increase the proportion of fine particles in the soil, so that the soil has better fluidity and impermeability. Its functions are making the muck have better drainability and reducing the torque of cutter head and the loss of water in formation. Better materials must be used during injection, and the puffing time must be mastered to achieve the adding effect. (3) Polymer system. Polymer injection system is suitable for non-cohesive soil, and it is often used in sandy pebble stratum with rich water content. The system is mainly used for binding water, reducing water-soil separation and increasing soil viscosity. The reflected functions are making the muck have better drainability and reducing the torque of cutter head and the loss of water in formation.

\section{Conclusion}

The basic principle of controlling shield construction risk: Geology is the foundation; Shield is the key; Man is fundamental; Technology is the support. Avoiding shield construction risks should be considered from three aspects: (1) Strengthen geological exploration to avoid geological risks; (2) Start with the adaptive design of shield machine, avoid equipment risks, start with professional management and control, avoid man-made risks. Obtaining detailed and reliable geological and hydrological data is the premise of safe and efficient shield construction; (3) Select shield equipment specially designed for stratum conditions is the key to the success of the project. Having an experienced, scientific management and a professional and efficient construction team is the fundamental guarantee for safe and efficient shield construction.

\section{References}

1. $\mathrm{Hu}$ Y, Yang G, Ma R, et al. Performance analysis of embedded continuous support track system for urban rail transit (in Chinese). Urban Mass Transit 2020; 23(7): 102-107.

2. Li Z, Wang C, Zhou S, et al. Analysis of the influence of the subgrade of a newly-built urban rail transit line in the soft soil area on the horizontal deformation of the subgrade of the adjacent existing line (in Chinese). Urban Mass Transit 2020; 23(7): 116-120.

3. Sun Y, Zhang G. Analysis of tendering of urban rail transit vehicle life cycle cost (in Chinese). Urban Mass Transit 2020; 23(7): 153-157. 